\title{
A Comparative Evaluation of Fracture Toughness of Composite Resin vs Protemp 4 for Use in Strip Crowns: An In Vitro Study
}

\author{
Vignesh $\mathrm{KC}^{1}$, Eswar Kandaswamy², Muthu $\mathrm{MS}^{3}$
}

\begin{abstract}
Aim: The aim of this study was to compare the fracture toughness of pedo shade packable composite resin (Z100, 3M ESPE, St. Paul, USA) vs Protemp 4 (3M ESPE, Seefeld, Germany) when used inside a strip crown to restore primary incisors.

Materials and methods: Thirty-six exfoliated noncarious human primary central and lateral incisors were randomly divided into two equal groups. The teeth were prepared to standardized dimensions to receive a strip crown. All the teeth were etched, rinsed, and dried following which bonding agent was applied and light cured. In group I, pedo shade packable composite resin (Z100, 3M ESPE, St. Paul, USA) was packed into strip crowns, placed on the prepared tooth, and light cured. In group II, the strip crowns were filled with Protemp 4 (3M ESPE, Seefeld, Germany), placed on the prepared tooth, and left to autopolymerize for 10 minutes. The strip crowns were removed, and the teeth were tested using the universal testing machine until fracture. Fracture toughness of the two groups was recorded and analyzed statistically using Student's " $t$ " test. Results: The mean force required to fracture strip crowns restored with Protemp $4(416.89 \pm 124.58 \mathrm{~N})$ was higher when compared with pedo shade packable composite resin $(338.27 \pm 130.99 \mathrm{~N})$. However, statistical analysis did not show a significant difference in the fracture toughness between the two groups $(p=0.074)$, based on Student's " $t$ " test results.

Conclusion: The fracture toughness of teeth restored with Protemp 4 was comparable with pedo shade packable composite resin when used inside a strip crown.

Clinical significance: The use of Protemp 4 is a possible alternative to pedo shade packable composite resin in restoring the primary anterior teeth, when used inside the strip crowns. The data also showed that the fracture toughness of Protemp 4 was comparable with pedo shade packable composite resin.
\end{abstract}

Keywords: Composite resin, Fracture toughness, Primary incisors, Protemp 4, Strip crowns.

International Journal of Clinical Pediatric Dentistry (2020): 10.5005/jp-journals-10005-1711

\section{INTRODUCTION}

Restoring decayed primary anterior teeth presents a challenge for the pediatric dentist. The challenge is to obtain an esthetic, long-lasting restoration capable of withstanding masticatory forces. ${ }^{1,2}$ The treatment options for restoring such teeth include open-faced stainless steel crowns, preveneered stainless steel crowns, zirconia crowns, polycarbonate crowns, artglass crowns, and strip crowns. ${ }^{3-10}$

Strip crowns have been used to restore decayed primary anterior teeth for more than 30 years..$^{10,11}$ Acid etch resin crowns or strip crowns serve as one of the most esthetic restorations for the pediatric dentist to restore decayed primary anterior teeth. Retention rates of strip crowns range from $63 \%$ to $100 \%$ over different follow-up periods. ${ }^{12-18}$ Parental satisfaction was found to be excellent for strip crowns. ${ }^{12}$ Salami et al. ${ }^{19}$ reported that strip crowns ranked lower than zirconia crowns but higher than preveneered stainless steel crowns in terms of overall parental satisfaction. ${ }^{19}$ However, strip crowns have specific limitations such as durability and color stability. ${ }^{9,20,21}$ They are technique sensitive and difficult to place. Additionally, their retention depends on the amount of tooth structure present after caries removal. ${ }^{11}$ Several modifications have been reported in the literature to improve the success rate of strip crowns. The use of mini pins, short posts, omega wire, and composite core posts has been reported to be successful in restoring teeth with little remaining coronal tooth structure. $^{4,14,22}$ The use of resin-modified glass ionomer cement ${ }^{23}$
${ }^{1-3}$ Centre for Early Childhood Caries Research (CECCRe), Department of Pediatric and Preventive Dentistry, Faculty of Dental Sciences, Sri Ramachandra Institute of Higher Education and Research (Deemed to be University), Chennai, Tamil Nadu, India

Corresponding Author: Vignesh KC, Centre for Early Childhood Caries Research (CECCRe), Department of Pediatric and Preventive Dentistry, Faculty of Dental Sciences, Sri Ramachandra Institute of Higher Education and Research (Deemed to be University), Chennai, Tamil Nadu, India, Phone: +91 9597905650, e-mail: drkcvignesh@gmail.com How to cite this article: Vignesh KC, Kandaswamy E, Muthu MS. A Comparative Evaluation of Fracture Toughness of Composite Resin vs Protemp 4 for Use in Strip Crowns: An In Vitro Study. Int J Clin Pediatr Dent 2020;13(1):57-60.

Source of support: This study was supported by Research Grant Number; Chancellor's Summer Research Fellowship for UG students/2014, from Sri Ramachandra University. Dr Mrinalini Shah from 3M ESPE, supplied the Protemp 4 material

Conflict of interest: None

and natural tooth fragments to restore primary incisors has also been reported in the literature. ${ }^{24}$

Dental material science advancements have made available newer generation of composites, bonding adhesive systems, and resin-based materials. Protemp 4 is a bis-acryl-based provisional resin consisting of an organic matrix and inorganic fillers. They are esthetically stable and have better color stability than polymethyl or

(c) The Author(s). 2020 Open Access This article is distributed under the terms of the Creative Commons Attribution 4.0 International License (https://creativecommons. org/licenses/by-nc/4.0/), which permits unrestricted use, distribution, and non-commercial reproduction in any medium, provided you give appropriate credit to the original author(s) and the source, provide a link to the Creative Commons license, and indicate if changes were made. The Creative Commons Public Domain Dedication waiver (http://creativecommons.org/publicdomain/zero/1.0/) applies to the data made available in this article, unless otherwise stated. 
polyethyl methacrylate. ${ }^{25-27}$ Mehrpour et al. ${ }^{28}$ described the flexural strength of different interim restorative materials (TempSpan, Protemp 4, Unifast III, Trim, and Revotek LC) with Protemp having high flexural strength among the materials tested. Amin et al. ${ }^{29}$ evaluated and found that Protemp 4 had the least marginal discrepancy among the provisional materials tested (Luxatemp Star, Visalys Temp, and polymethyl methacrylate).

There have been no reported studies in the literature on the use of Protemp 4 (3M ESPE) in primary anterior teeth, inside the strip crown. Therefore, the purpose of this in vitro study was to compare the fracture toughness of Protemp 4 (3M ESPE, Seefeld, Germany) vs pedo shade packable composite resin (Z100, 3M ESPE, St. Paul, USA) when used inside a strip crown to restore primary incisors.

\section{Materials and Methods}

Approval for the study protocol was obtained from Institutional Review Board (for student projects) of Sri Ramachandra University, Chennai (CSP/14/AUG/36/114). In this in vitro study, 36 exfoliated human primary maxillary and mandibular central and lateral incisors were collected and stored in isotonic saline at $37^{\circ} \mathrm{C}$, until it was used for the study. Teeth that were used showed no evidence of dental caries or any fracture. All the teeth were cleaned of gross debris using an ultrasonic scaler (Magbole, Guangzhou, China). They were embedded in a block of self-cure acrylic resin (DPI-RR cold cure pink, Denture base polymer resins, Dental Products of India, Mumbai), using a rigid plastic template. The teeth were numbered separately, and the three dimensions (buccolingual, mesiodistal, and cervicoincisal) were measured by two investigators independently using a Vernier caliper (SV-08 Stainless Steel Digital Vernier Caliper, E-Base Measuring Tools Co., Aluminum Ruler Manufacturer, Taiwan), and the mean was taken to establish baseline dimensions to guide the tooth preparation. The buccolingual dimension was measured at the greatest curvature of the tooth at the cingulum region. The mesiodistal dimension was measured at the greatest dimension of the tooth mesiodistally. The cervicoincisal dimension was measured at the buccal surface from the most apical point of the cervical line to the incisal edge.

The crowns of the teeth were prepared to receive a full coverage restoration with a strip crown. A TF-12 diamond bur (Mani Inc., Germany) was used with a high-speed hand piece under water cooling. Care was taken to ensure parallelism of the proximal surfaces. The teeth samples were prepared so as to have a buccolingual width of $3.5 \mathrm{~mm}$, a mesiodistal width of 4 $\mathrm{mm}$, and a cervicoincisal length of $4 \mathrm{~mm}$. All the aforementioned measurements were made using a Vernier caliper by the two investigators independently and recorded. A kappa value of 0.74 was obtained for the values measured by the two investigators. The strip crown (size B2) of primary maxillary left lateral incisor (3M ESPE, St. Paul, USA) was checked with the tooth and used for both the groups.

The strip crowns were trimmed off using sharp-curved scissors according to the manufacturer's instructions, and vent holes were placed on the palatal surface to ensure escape of air and excess material. The teeth in both the groups were dried and etched (Scotchbond Multi-purpose Etchant, 3M ESPE, St. Paul, USA) for 15 seconds. ${ }^{12}$ The etchant was rinsed off, and the dentin surface was dried with gentle air spray, taking care not to overdry the tooth. The bonding agent (Adper Single Bond, 3M ESPE, St. Paul, USA) was applied and light-cured (Bluedent LED, Smart, Bulgaria) for 20 seconds at $1,200 \mathrm{~mW} / \mathrm{cm}^{2}$.

The teeth were randomly divided into two groups at this stage.

Group I (pedo shade packable composite resin group) - teeth which received a full coverage restoration with pedo shade packable composite resin (Z100, 3M ESPE, St. Paul, USA), inside the strip crown.

Group II (Protemp group) — teeth which received a full coverage restoration with Protemp 4 (3M ESPE, Seefeld, Germany; A2 shade), inside the strip crown.

In group I, pedo shade packable composite resin (Z100, 3M ESPE, St. Paul, USA) was packed into the strip crown. In group II, the strip crowns were filled with Protemp 4 (3M ESPE, Neuss, Germany). In all the samples, care was taken to avoid void formation. The strip crown was seated on the tooth gently, and the excess material was removed using a sharp explorer. Group I was light-cured through the strip crown as per the manufacturer's instructions (labially for 40 seconds and lingually for 40 seconds) at 1,200 mW/ $\mathrm{cm}^{2}$. Group II was left to autopolymerize for 10 minutes at room temperature.

The strip crown was then removed by cutting it on the lingual surface with a spoon excavator (GDC Marketing, India). The crowns were stripped off from the tooth. The teeth were stored in isotonic saline for 24 hours prior to testing for fracture toughness. The samples were tested for fracture toughness using a universal testing machine (Instron, Blue Hill 2 Version, Pneumatic Side Action Grips, India). The force was applied at the incisal edges of the crown at a crosshead speed of $1 \mathrm{~mm} /$ minute, and the force of fracture was recorded in Newton ( $\mathrm{N}$ ).

Statistical analysis was done using SPSS 16.0 statistical analysis software (SPSS Inc., Chicago III., USA). Mean and standard deviations were calculated. Student's " $t$ " test was used to compare the results between the groups $(p<0.05)$.

\section{Results}

The fracture toughness of the two groups (pedo shade packable composite resin and Protemp) is shown in Table 1. The difference in the fracture toughness between the two groups was not found to be statistically significant $(p=0.074)$ based on Student's " $t$ " test results.

\section{Discussion}

Full coverage restorations are often required for primary anterior teeth that are affected by early childhood caries and traumatic dental injuries. ${ }^{30}$ Several treatment options (such as strip crowns, prestainless steel crowns, and zirconia crowns) are reported in the literature for restoring decayed primary anterior teeth. ${ }^{3,4,6,7,9,11,12,15,23,30-40}$ Although strip crowns have been in clinical use for more than 30 years, most of the published data about strip crowns are in the form of retrospective studies, parental satisfaction, case reports, and clinical performance. ${ }^{4,11,12,15,37,38,41}$ In vitro testing

Table 1: Fracture toughness values of two groups

\begin{tabular}{lllll}
\hline Groups $(n=18)$ & Mean $(N)$ & $\begin{array}{l}\text { Standard } \\
\text { deviation }(N)\end{array}$ & t value & p value \\
\hline $\begin{array}{l}\text { I (pedo shade packable } \\
\text { composite resin) }\end{array}$ & 338.27 & 130.99 & 1.845 & $0.074^{*}$ \\
II (Protemp) & 416.89 & 124.58 & & \\
\hline
\end{tabular}

*There is no statistical significant difference between the two groups $(p<$ $0.05)$ 
of the mechanical and physical properties of the dental materials serves as a benchmark for its use in clinical practice. ${ }^{42}$ However, to the best of our knowledge, there are no published in vitro studies evaluating the mechanical properties of human primary incisor teeth restored using a strip crown. Hence, the methodology used in this study was adapted from similar studies.

This study was designed to compare the fracture toughness of pedo shade packable composite resin vs Protemp 4, for its use in strip crowns. Although Protemp 4 is a provision material, it contains bisphenol A-glycidyl methacrylate which is commonly found in the resin component of composite resins. Hence, we modified the technique described by McLaren ${ }^{43}$ to etch and bond Protemp 4 to tooth structure.

In this study, Protemp 4 had higher fracture strength values than pedo shade packable composite resin, but the result was not statistically significant. The probable reasons for this could be due to the relatively small sample size and the varying amounts of dentin exposed during tooth preparation. All the samples were prepared to a standard size, to ensure uniformity of the final samples tested. Since both primary central and lateral incisors were used for this study, there is a possibility that varying amounts of dentin may be exposed and act as the bonding substrate. This could be a potential limitation of this study, since it can cause variability in the strength values. Protemp 4 had been used with a dispensing tip in a mixing gun. ${ }^{29}$ Dispensing methods of Protemp 4 into strip crowns need further research due to the larger size of the dispensing tip when compared with the size of the crown. In pediatric dentistry, dispensing tips or cartridges of Protemp 4 can be made specifically for use in future.

Color stability is also another factor to be considered when restoring teeth using a strip crown. Further research is necessary to evaluate the color stability of Protemp 4. Protemp 4 being a selfpolymerizing resin undergoes an exothermic reaction during the setting stage. Khajuria et al. ${ }^{44}$ proved that Protemp 4 caused less intrapulpal temperature change and less exothermic heat when compared with other provisional materials. ${ }^{44}$ However, the effect on primary tooth is yet to be investigated. Protemp 4 can also be used in a two-step process where it can be fabricated, followed by cementation with resin cements. The effect of temperature can be eliminated, if a two-step procedure (fabrication and cementation) is used to fabricate and cement the strip crown.

This study provides a preliminary assessment into the use of a new material for an existing treatment modality. However, the clinical situation cannot be reproduced through the test performed in this study. The obtained values for fracture toughness of the groups should be regarded as a preliminary indicator of the strength of the material when used for the strip crown. ${ }^{45}$ Consequently, further studies are required to investigate the performance of the primary anterior teeth restored by strip crown under cyclic stress to simulate the normal loading conditions. Further research is also needed to compare the clinical performance of pedo shade packable composite resin and Protemp 4 using strip crowns to provide reliable data for future decision-making.

\section{Conclusion}

Within the limitations of this in vitro study, it is concluded that the fracture toughness of Protemp 4 was comparable to pedo shade packable composite resin when used inside the strip crown.

\section{Clinical Significance}

The use of Protemp 4 is a possible alternative to pedo shade packable composite resin in restoring the primary anterior teeth, when used inside the strip crowns. The data also showed that the fracture toughness of Protemp 4 was comparable to pedo shade packable composite resin.

\section{ACKNoWledgments}

This study was supported by the research grant from the Chancellor's Summer Research Fellowship for Under Graduate Students in 2014, from Sri Ramachandra University. We also thank Dr Mrinalini Shah from 3M ESPE for supplying the Protemp 4 material.

\section{References}

1. Gupta M, Chen J, Ontiveros JC. Veneer retention of preveneered primary stainless steel crowns after crimping. J Dent Child 2008;75(1):44-47.

2. Waggoner WF, Cohen $\mathrm{H}$. Failure strength of four veneered primary stainless steel crowns. Pediatr Dent 1995;17(1):36-40.

3. Marquezin MCS, Zancopé BR, Pacheco LF, et al. Aesthetic and functional rehabilitation of the primary dentition affected by amelogenesis imperfecta. Case Rep Dent 2015;2015:1-6. DOI: 10.1155/2015/790890.

4. Carranza F, García-Godoy F. Esthetic restoration of primary incisors. Am J Dent 1999;12(2):55-58.

5. Hartmann CR. The open-face stainless steel crown: an esthetic technique. ASDC J Dent Child 1983;50(1):31-33.

6. ElBadrawy HE, Diab M. Treatment of cariously involved fused maxillary primary lateral and central incisors. Pediatr Dent 2011;23(4):363-364.

7. Croll TP, Helpin ML. Preformed resin-veneered stainless steel crowns for restoration of primary incisors. Quintessence Int 1996;27(5): 309-313.

8. MacLean JK, Champagne CE, Waggoner WF, et al. Clinical outcomes for primary anterior teeth treated with preveneered stainless steel crowns. Pediatr Dent 2007;29(5):377-381.

9. Shah PV, Lee JY, Wright JT. Clinical success and parental satisfaction with anterior preveneered primary stainless steel crowns. Pediatr Dent 2004;26(5):391-395.

10. Lee JK. Restoration of primary anterior teeth: review of the literature. Pediatr Dent 2002;24(5):506-510.

11. Kupietzky A. Bonded resin composite strip crowns for primary incisors: clinical tips for a successful outcome. Pediatr Dent 2002;24(2):145-148.

12. Kupietzky A, Waggoner WF, Galea J. The clinical and radiographic success of bonded resin composite strip crowns for primary incisors. Pediatr Dent 2003;25(6):577-581.

13. Kupietzky A, Waggoner WF, Galea J. Long-term photographic and radiographic assessment of bonded resin composite strip crowns for primary incisors: results after 3 years. Pediatr Dent 2005;27(3): 221-225.

14. Mortada A, King NM. A simplified technique for the restoration of severely mutilated primary anterior teeth. J Clin Pediatr Dent 2004;28(3):187-192. DOI: 10.17796/jcpd.28.3.2554xv412644ru13.

15. Ram D, Fuks AB. Clinical performance of resin-bonded composite strip crowns in primary incisors: a retrospective study. Int J Ped Dent 2006;16:49-54. DOI: 10.1111/j.1365-263X.2006.00680.x.

16. Su HL, Chen PS. A clinical evaluation of comprehensive dental treatment for children under general anesthesia. Changgeng Yi Xue Za Zhi 1992;15(4):188-192.

17. Eidelman E, Faibis S, Peretz B. A comparison of restorations for children with early childhood caries treated under general anesthesia or conscious sedation. Pediatr Dent 2000;22(1):33-37. 
18. O'Sullivan EA, Curzon ME. The efficacy of comprehensive dental care for children under the general anesthesia. Br Dent J 1991;171(2):56-58. DOI: $10.1038 /$ sj.bdj.4807603.

19. Salami A, Walia T, Bashiri R. Comparison of parental satisfaction with three tooth-Colored full-coronal restorations in primary maxillary incisors. J Clin Pediatr Dent 2015;39(5):423-428. DOI: 10.17796/10534628-39.5.423.

20. Tate $\mathrm{AR}, \mathrm{Ng} \mathrm{MW}$, Needleman $\mathrm{HL}$, et al. Failure rates of restorative procedures following dental rehabilitation under general anesthesia. Pediatr Dent 2002;24(1):69-71.

21. Roberts C, Lee JY, Wright JT. Clinical evaluation of and parental satisfaction with resin-faced stainless steel crowns. Pediatr Dent 2001;23(1):28-31.

22. Judd PL, Kenny DJ, Johnston DH, et al. Composite resin shortpost technique for primary anterior teeth. J Am Dent Assoc 1990;120(5):553-555. DOI: 10.14219/jada.archive.1990.0071.

23. Nelson T. An improved interim therapeutic restoration technique for management of anterior early childhood caries: report of two cases. Pediatr Dent 2013;35(4):124-128.

24. Duhan H, Pandit IK, Srivastava N, et al. Clinical comparison of various esthetic restorative options for coronal build-up of primary anterior teeth. Dent Res J (Isfahan) 2015;12(6):574-580. DOI: 10.4103/17353327.170578.

25. Wassell RW, St George G, Ingledew RP, et al. Crowns and other extracoronal restorations: provisional restorations. Br Dent J 2002;15: 619-630. DOI: 10.1038/sj.bdj.4801443.

26. Tjan AH, Castelnuovo J, Shiotsu G. Marginal fidelity of crowns fabricated from six proprietary provisional materials. J Prosthet Dent 1997;77(5):482-485. DOI: 10.1016/S0022-3913(97)70140-9.

27. Lang $R$, Rosentritt $M$, Leibrock $A$, et al. Colour stability of provisional crown and bridge restoration materials. Br Dent J 1998;185(9): 468-471. DOI: 10.1038/sj.bdj.4809839.

28. Mehrpour H, Farjood E, Giti R, et al. Evaluation of the flexural strength of interim restorative materials in fixed prosthodontics.J Dent (Shiraz) 2016;17(3):201-206.

29. Amin BM, Aras MA, Chitre V. A comparative evaluation of the marginal accuracy of crowns fabricated from four commercially available provisional materials: an in vitro study. Contemp Clin Dent 2015;6(2):161-165. DOI: 10.4103/0976-237X.156035.

30. Champagne C, Waggoner W, Ditmyer M, et al. Parental satisfaction with preveneered stainless steel crowns for primary anterior teeth. Pediatr Dent 2007;29(6):465-469.

31. Mittal NP. Restoring the smile: inexpensive biologic restorations. Dent Res J 2014;11(3):415-421.

32. Jeong $M-A, \operatorname{Kim} A-H$, Shim $Y-S$, et al. Restoration of strip crown with a resin-bonded composite cement in early childhood caries. Case Rep Dent 2013;2013:581934. DOI: 10.1155/2013/581934.
33. Jain $M$, Singla $S$, Bhushan $B$, et al. Esthetic rehabilitation of anterior primary teeth using polyethylene fiber with two different approaches. J Indian Soc Pedod Prev Dent 2011;29(4):327-332. DOI: 10.4103/0970-4388.86381.

34. Navit S, Katiyar A, Samadi F, et al. Rehabilitation of severely mutilated teeth under general anesthesia in an emotionally immature child. $J$ Indian Soc Pedod Prev Dent 2010;28(1):42-44. DOI: 10.4103/09704388.60476.

35. BayrakS, Tunc ES, Tuloglu N. Polyethylene fiber-reinforced composite resin used as a short post in severely decayed primary anterior teeth: a case report. Oral Surg Oral Med Oral Pathol Oral Radiol Endod 2009;107(5):e60-e64. DOI: 10.1016/j.tripleo.2008.12.051.

36. Usha M, Deepak V, Venkat S, et al. Treatment of severely mutilated incisors: a challenge to the pedodontist. J Indian Soc Pedod Prev Dent 2007;25(Suppl):S34-S36.

37. Mendes FM, De Benedetto MS, Del Conte Zardetto CG, et al. Correa MSNP. resin composite restoration in primary anterior teeth using short post technique and strip crowns: a case report. Quintessence Int 2004;35(9):689-692.

38. Margolis FS. The sandwich technique and strip crowns: an esthetic restoration for primary incisors. Compend Contin Educ Dent 2002;23(12):1165-1169. quiz1170.

39. Kupietzky API, Waggoner WF. Parental satisfaction with bonded resin composite strip crowns for primary incisors. Pediatr Dent 2004;26(4):337-340.

40. Ashima G, Sarabjot KB, Gauba K, et al. Zirconia crowns for rehabilitation of decayed primary incisors: an esthetic alternative. $J$ Clin Pediatr Dent 2014;39(1):18-22. DOI: 10.17796/jcpd.39.1.t6725r5 566u4330g.

41. Planells del Pozo P, Fuks AB. Zirconia crowns-an esthetic and resistant restorative alternative for ECC affected primary teeth. J Clin Pediatr Dent 2014;38(3):193-195. DOI: 10.17796/jcpd.38.3.0255 q84jt2851311.

42. Bayne SC. Correlation of clinical performance with "in vitro test" of restorative dental materials that use polymer-based matrices. Dent Mater 2012;28(1):52-71. DOI: 10.1016/j.dental.2011.08.594.

43. McLaren EA. Bonded functional esthetic prototype: an alternative pre-treatment mock-up technique and cost-effective mediumterm esthetic solution. Compend Contin Educ Dent 2013;34(8): 596-607.

44. Khajuria RR, Madan R, Agarwal S, et al. Comparison of temperature rise in pulp chamber during polymerization of materials used for direct fabrication of provisional restorations: an in vitro study. Eur J Dent 2015;9(2):194-200. DOI: 10.4103/1305-7456.156807.

45. Rosen M, Klompas J, Becker PJ. Bond strength values: should they be considered in material selection? J Dent Assoc S Afr 1995;50(5): 197-202. 